\title{
Spectroscopic properties of rare earth ions in tellurite glass
}

\author{
M. Reben, ${ }^{* 1}$ B. Burtan, ${ }^{2}$ J. Cisowski, ${ }^{2}$ J. Wasylak, ${ }^{1}$ \\ ${ }^{I}$ Faculty of Materials Sciences and Ceramics, AGH - University of Science and Technology, Al. Mickiewicza 30, \\ 30-059 Cracow, Poland, \\ ${ }^{2}$ Institute of Physics, Cracow University of Technology, ul. Podchorązych 1, 30-084 Cracow, Poland
}

Received October 30, 2012; accepted December 18, 2012; published December 31, 2012

\begin{abstract}
Spectroscopic and optical properties of rare earth ions: $\mathrm{Tb}^{3+}, \mathrm{Eu}^{3+}, \mathrm{Er}^{3+}, \mathrm{Pr}^{3+}, \mathrm{Nd}^{3+}$ ions in multicomponent tellurite-tungstate glass have been investigated. The spectral dependence of ellipsometric angles of the tellurite glass rare earth (RE) doped, have been studied. The optical measurements were conducted on Woollam M2000 spectroscopic ellipsometer, in a spectral range of 190-1700nm. The reflectance and transmittance measurements have been done.
\end{abstract}

Tellurite glasses find increasing and wide applications in modern science and technology due to their physicchemical properties. Among these the tellurite glasses based on $\mathrm{WO}_{3}$ and other heavy metal oxides, known to have a high linear refractive index, are promising material for IR technologies, nonlinear optics and considered as perspective materials for fiber optics [1-4]. Moreover, the rare-earth-ion-doped tellurite glasses have attracted much interest recently because they can be used as a host for solid-state lasers [5]. They have many attractive features for a broadband optical amplifier because of their low phonon energy and high refractive index [6]. In this paper we report the study of spectroscopic properties of $\mathrm{Pr}^{3+}$, $\mathrm{Er}^{3+}, \mathrm{Eu}^{3+}, \mathrm{Tb}^{3+}$ and $\mathrm{Nd}^{3+}$ doped lead - tungsten lanthanum - tellurite glasses.

Tellurite glasses from the $\mathrm{TeO}_{2}-\mathrm{WO}_{3}-\mathrm{PbO}-\mathrm{La}_{2} \mathrm{O}_{3}$ system were obtained by melting $25 \mathrm{~g}$ batches in gold crucibles in an electric furnace at a temperature of $850^{\circ} \mathrm{C}$ in the air atmosphere. The crucibles were covered with a platinum plate to avoid vaporization losses. The melts were poured out onto a steel plate forming a layer of 2 to $5 \mathrm{~mm}$, then annealed in the temperature range of $320-340^{\circ} \mathrm{C}$ for 12 hours. The chemicals employed with their high (99.99\%) purity were as follows: $\mathrm{TeO}_{2}(60 \mathrm{~mol} \%), \mathrm{WO}_{3}(27$ mol\%), $\mathrm{PbO}(10 \mathrm{~mol} \%)$ and $\mathrm{La}_{2} \mathrm{O}_{3}(3 \mathrm{~mol} \%)$. In order to introduce the rare-earth ions such as $\mathrm{Tb}^{3+}, \mathrm{Eu}^{3+}, \mathrm{Pr}^{3+}, \mathrm{Nd}^{3+}$ and $\mathrm{Er}^{3+}$ into the tellurite glass matrix, the respective oxides of an amount of $0.1 \mathrm{~g}$ have been added to the batch. The chemical composition of obtained glasses is shown in Table 1.

The ellipsometric data were collected with a M-2000 Woollam ellipsometer in the spectral range 190-1700nm.
The knowledge of $\Psi$ and $\Delta$ allows one to determine not only the dispersion of the optical constants but also roughness $\sigma$ of a glass [7]. The samples have been measured for three angles of incidence, namely $65^{\circ}, 70^{\circ}$ and $75^{\circ}$. To analyze the data, we have combined all the angular spectra and we have fitted all the data simultaneously. The data have been analyzed using CompleteEASE 4.1 software.

In order to determine the spectral dependences of reflectance $R(\lambda)$ and transmittance $T(\lambda)$ of the investigated samples, a JASCO V-570 double-beam spectrophotometer operating in the range 190-2500nm was used.

Table 1. Chemical composition of tellurite glasses RE doped.

\begin{tabular}{|c|c|c|c|c|c|c|}
\hline \multirow{2}{*}{$\begin{array}{c}\text { Glass } \\
\text { ID }\end{array}$} & \multicolumn{4}{|c|}{ Composition, mol\% } & \multirow{2}{*}{$\begin{array}{c}\begin{array}{c}\text { Molar } \\
\text { concent. } \\
{\left[\mathrm{mol} / \mathrm{dm}^{3}\right]}\end{array} \\
\mathrm{RE}^{3+}\end{array}$} & \multirow{2}{*}{$\begin{array}{c}\begin{array}{c}\text { Ions } \\
\text { concent. } \\
{\left[\mathrm{cm}^{-1}\right]}\end{array} \\
\mathrm{RE}^{3+}\end{array}$} \\
\hline & $\mathrm{TeO}_{2}$ & $\mathrm{WO}_{3}$ & $\mathrm{PbO}$ & $\mathrm{La}_{2} \mathrm{O}_{3}$ & & \\
\hline $\mathrm{BB}$ & 60 & 27 & 10 & 3 & - & - \\
\hline $\mathrm{BBTb}$ & 60 & 27 & 10 & 3 & 0.1405 & $8.46 \times 10^{19}$ \\
\hline $\mathrm{BBNd}$ & 60 & 27 & 10 & 3 & 0.1523 & $9.17 \times 10^{19}$ \\
\hline $\mathrm{BBEu}$ & 60 & 27 & 10 & 3 & 0.1460 & $8.79 \times 10^{19}$ \\
\hline BBEr & 60 & 27 & 10 & 3 & 0.1340 & $8.07 \times 10^{19}$ \\
\hline $\mathrm{BBPr}$ & 60 & 27 & 10 & 3 & 0.1504 & $9.06 \times 10^{19}$ \\
\hline
\end{tabular}

The spectroscopic ellipsometry measurements have been performed to get the dispersion relation for the refractive index $n$. The spectroscopic ellipsometry allows also to determine the surface roughness $\sigma$. For our samples we assumed the appearance of the surface roughness which can be described using the Bruggeman effective medium approximation (EMA) [8]. This approximation uses a 50:50 mixture of the material and air at the sample surface to get the optical constants that approximate the effect of the surface roughness. The obtained values of $\sigma$, are presented in column 5 of Table 1. These values appear to be typical for polished glasses. The spectral dependence $n(\lambda)$ obtained in the range 190$1700 \mathrm{~nm}$ from the fitting procedure for the studied glasses are shown in Fig. 1

\footnotetext{
*E-mail: manuelar@agh.edu.pl
} 


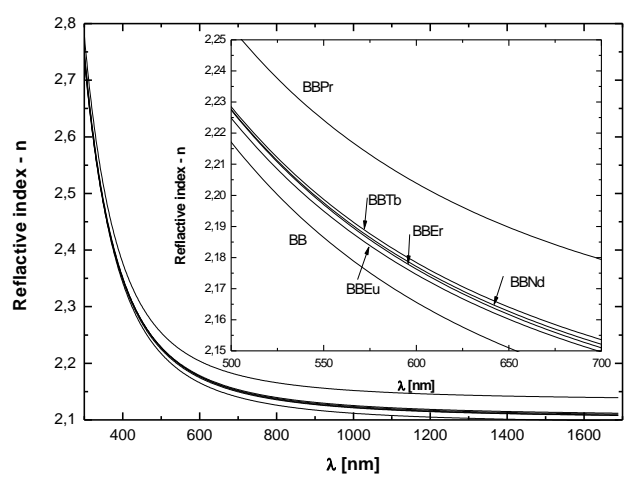

Fig. 1. Dispersion of the refraction coefficient obtained for the investigated glasses from ellipsometric measurements.

As seen, the dispersion of the refraction coefficient is practically the same for the studied samples.However, the highest value of refractive index is observed for sample BBPr (Fig. 1).

Refractive index dispersion was applied, being expressed by the following formula (Cauchy model):

$$
n(\lambda)=A+\frac{B}{\lambda^{2}}+\frac{C}{\lambda^{4}},
$$

where $A, B$ and $C$ are the fitting parameters.

The values of the Cauchy parameters $A, B$ and $C$ along with the surface roughness determined from the fitting procedure are presented in Table 2.

Table 2. The values of optical parameters obtained from ellipsometric studies.

\begin{tabular}{|c|c|c|c|c|c|}
\hline ID & $\begin{array}{c}n \\
@ 633 n m\end{array}$ & $A$ & $B$ & $C$ & $\begin{array}{c}\text { Roughness } \\
(\mathrm{nm})\end{array}$ \\
\hline $\mathrm{BB}$ & 2.155 & 2.092 & 0.01547 & 0.00393 & 10.4 \\
\hline $\mathrm{BBNd}$ & 1.167 & 2.104 & 0.01586 & 0.00376 & 6.4 \\
\hline $\mathrm{BBEr}$ & 2.166 & 2.102 & 0.01606 & 0.00380 & 8.4 \\
\hline $\mathrm{BBEu}$ & 2.164 & 2.102 & 0.01576 & 0.00375 & 8.1 \\
\hline $\mathrm{BBTb}$ & 2.168 & 2.106 & 0.01580 & 0.00371 & 7.1 \\
\hline $\mathrm{BBPr}$ & 2.194 & 2.134 & 0.01432 & 0.00394 & 5.1 \\
\hline
\end{tabular}

The refractive index of tellurite glasses exhibit very high values, over 2.3, within the 400-450nm spectral range which are considerably higher than those obtained for standard optical glasses. The ellipsometric studies have proved that the presence of $\mathrm{Nd}^{3+}, \mathrm{Tb}^{3+}, \mathrm{Eu}^{3+}$ and $\mathrm{Er}^{3+}$ ions does not practically change the refractive index of the tellurite glass matrix.

The specular reflectance and transmittance spectra have been gathered for the tellurite glass matrix (BB) and for the matrix doped with $\mathrm{Nd}^{3+}(\mathrm{BBNd}), \mathrm{Er}^{3+}$ (BBEr), $\mathrm{Eu}^{3+}$ $(\mathrm{BBEu}), \mathrm{Tb}^{3+}(\mathrm{BBTb})$ and $\mathrm{Pr}^{3+}$ (BBPr). A comparison between parent glass and rare-earth ion doped glasses is shown in Figs. 2-6. It can be seen that an introduction of small amounts of rare-earth ions results in a dramatic change in the spectra; instead of smooth dependences observed for the reference (undoped) glass BB. There are a number of narrow absorption bands, seen not only in the transmittance- but also in the reflectance spectra, which correspond to characteristic transitions between the ground- and consecutive excited states of $\mathrm{Nd}^{3+}[9], \mathrm{Er}^{3+}$ [10], $\mathrm{Eu}^{3+}, \mathrm{Tb}^{3+}$, and $\mathrm{Pr}^{3+}$ ions[11].

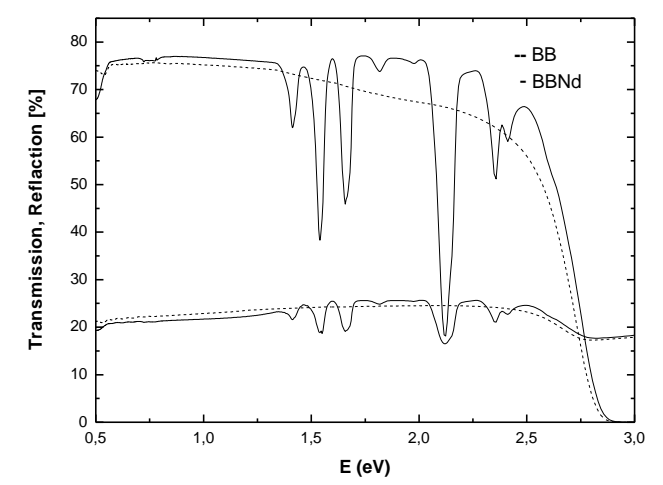

Fig.2. Specular reflectance and transmittance spectra of tellurite glass doped with $\mathrm{Nd}^{3+}$ ions (sample BBNd) in comparison to the spectra of the undoped tellurite glass matrix (sample BB).

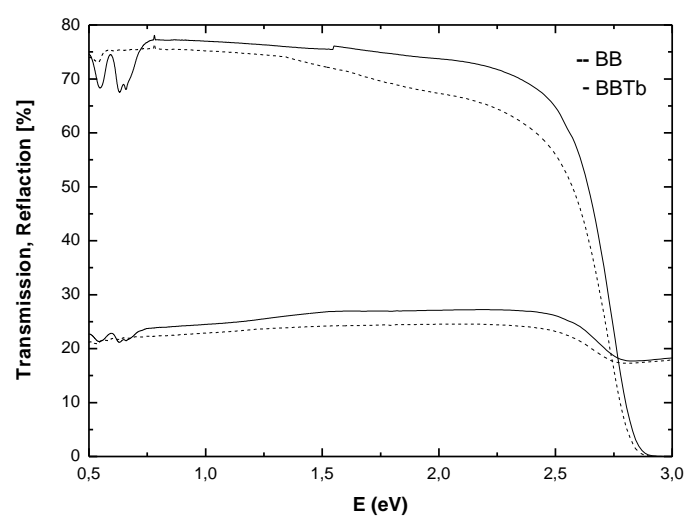

Fig.3. Specular reflectance and transmittance spectra of tellurite glass doped with $\mathrm{Tb}^{3+}$ ions (sample BBTb) in comparison to the spectra of the undoped tellurite glass matrix (sample BB).

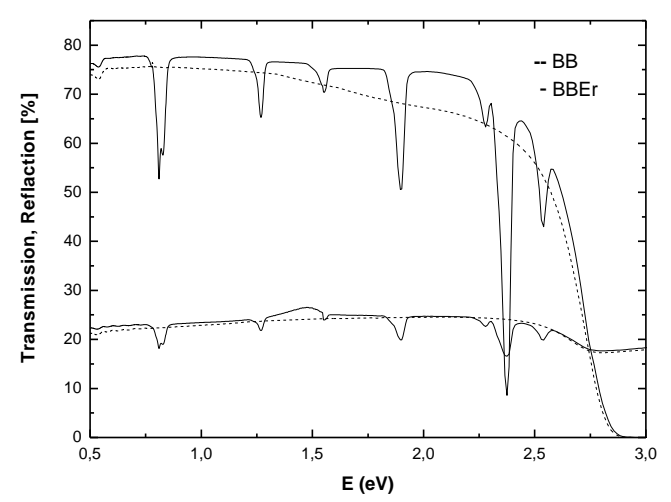

Fig.4. Specular reflectance and transmittance spectra of tellurite glass doped with $\mathrm{Er}^{3+}$ ions (sample BBEr) in comparison to the spectra of the undoped tellurite glass matrix (sample BB). 


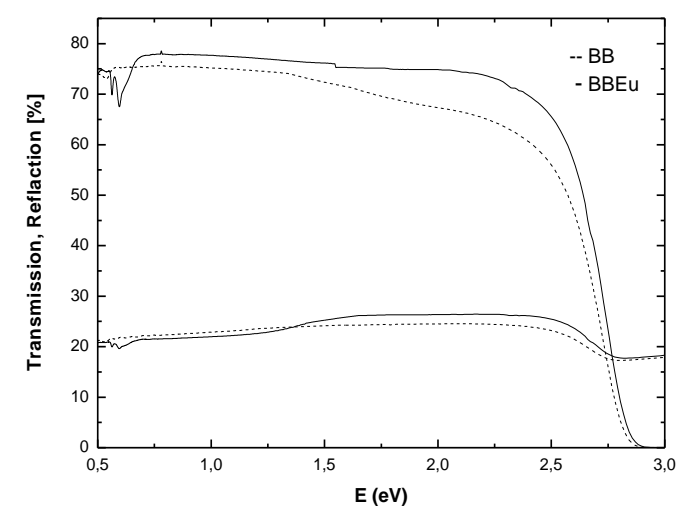

Fig.5. Specular reflectance and transmittance spectra of tellurite glass doped with $\mathrm{Eu}^{3+}$ ions (sample $\mathrm{BBEu}$ ) in comparison to the spectra of the undoped tellurite glass matrix (sample BB).

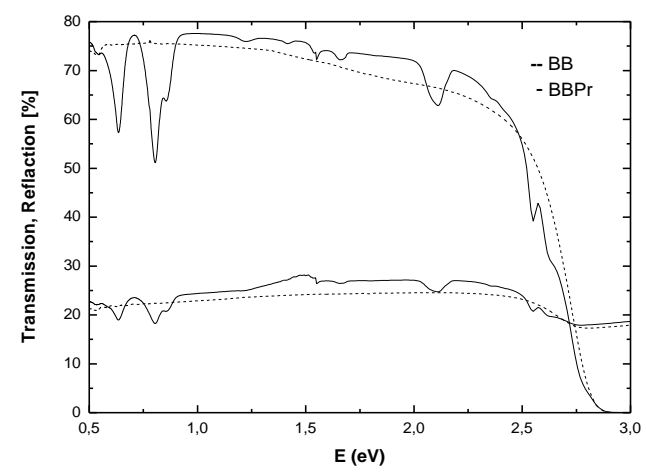

Fig.6. Specular reflectance and transmittance spectra of tellurite glass doped with $\mathrm{Pr}^{3+}$ ions (sample BBPr) in comparison to the spectra of the undoped tellurite glass matrix (sample BB).

A comparison of the absorbance spectra of the investigated glass samples is shown in Fig. 7.

It can be seen that, above the smooth absorbance of the undoped sample $\mathrm{BB}$, there are sequences of absorption peaks which are quite different for the tellurite glass doped with $\mathrm{Nd}^{3+}, \mathrm{Er}^{3+}$ in comparison to that doped with $\mathrm{Eu}^{3+}, \mathrm{Tb}^{3+}$ and $\mathrm{Pr}^{3+}$ ions. On the other hand, above 2.6 $\mathrm{eV}$, all the absorbance curves merge into one which corresponds to the onset of absorption of the tellurite glass matrix.

In summary, we have shown that the presence of $\mathrm{Nd}^{3+}$, $\mathrm{Tb}^{3+}, \mathrm{Eu}^{3+}, \mathrm{Pr}^{3+}$ and $\mathrm{Er}^{3+}$ ions in the $\mathrm{TeO}_{2}-\mathrm{WO}_{3}-\mathrm{PbO}-$ $\mathrm{La}_{2} \mathrm{O}_{3}$ glass system strongly affects the optical spectra exhibiting a number of narrow absorption bands which correspond to characteristic transitions between the ground-

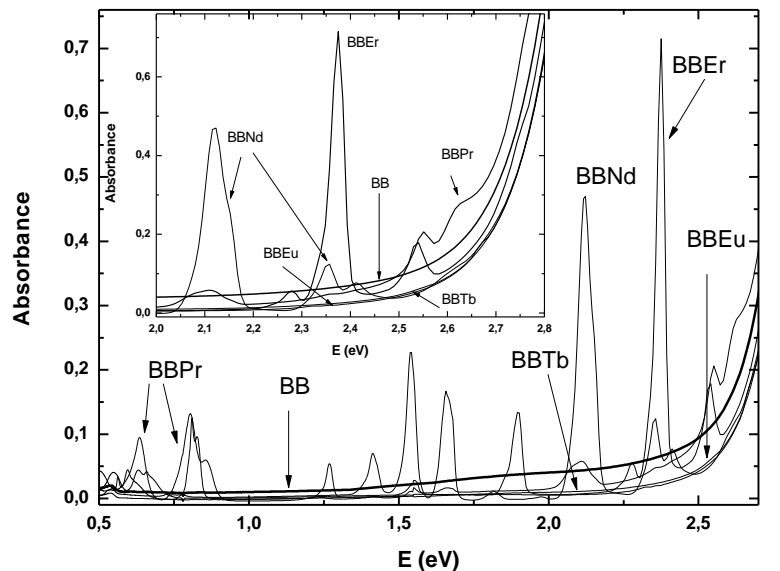

Fig.7. Absorbance spectra of tellurite glass doped with $\mathrm{Nd}^{3+}$ (sample BBNd), $\mathrm{Er}^{3+}$ (sample BBEr), Eu ${ }^{3+}$ (sample BBEu), $\mathrm{Tb}^{3+}$ (sample BBTb) and $\mathrm{Pr}^{3+}$ ions (sample BBPr) in comparison to the spectrum of the undoped tellurite glass matrix (sample BB).

and consecutive excited states of rare-earth ions. On the basis of spectrophotometric, transmittance reaches about $80 \%$ for all the studies tellurite glasses doped with rare earth ions. On the other hand, as found from the ellipsometric studies, the values and dispersion of the refractive index are practically the same for the undoped tellurite glass matrix and for the matrix doped with $\mathrm{Nd}^{3+}$, $\mathrm{Tb}^{3+}, \mathrm{Eu}^{3+}$ and $\mathrm{Er}^{3+}$ except for $\mathrm{Pr}^{3+}$ ions.

The work was supported by the Faculty of Materials Science and Ceramics AGH: University of Science and Technology, founding no. 11.11.160.365 (2012).

\section{References}

[1] R. El-Mallawany, Tellurite Glasses Handbook (CRC press, London/New York/Washington 2002).

[2] L. Shaltout, Y. Tang, R. Braunstein, E.E. Shaisha, J. Phys. Chem. Solids 57(9), 1223 (1996).

[3] P. Mergo et al., Proc. SPIE 7120, 712009 (2008).

[4] T. Kosuge, Y.Benino, V. Dimitrov, R. Sato, T. Komatsu, J. Non-Cryst. Solids 242 (2-3), 154 (1998).

[5] G. X. Chen, Q. Y. Zhang, G. F. Yang, Z. H. Jiang, J. Fluorensc. 17, 301 (2007).

[6] J. S. Wang, E. M. Vogel, E. Snitzer, Opt. Mater. 3, 187 (1994).

[7] G.E. Jellison, Thin Solid Films 313-314, 33 (1998).

[8] B. Johs, C.M. Herzinger, J.H. Dinan, A. Cornfeld, J.D. Benson, Thin Solid Films 313-314, 137 (1998).

[9] S.S. Babu, R. Rajeswari, K. Jang, C.E. Jin, K.H. Jang, J. Luminescence 130, 1021 (2010).

[10] H.W. Li, S.Q. Man, Opt. Comm. 282, 1579 (2009).

[11] M. Malinowski, Lasery świattowodowe (Oficyna Wydawnicza Politechniki Warszawskiej 2003). 